\title{
VALORISATION OF FLY ASHES BY GEOPOLYMERISATION
}

\author{
J.L. PROVIS* \\ P. DUXSON \\ R.M. HARREX \\ C-Z. YONG \\ J.S.J. VAN DEVENTER
}

Received: $11 / 09 / 08$

Accepted: 30/10/08

\author{
Department of Chemical and Biomolecular Engineering \\ University of Melbourne, Victoria 3010, Australia \\ "Permanent address: BRE, Bucknalls Lane \\ Watford WD25 9XX, United Kingdom
}

\begin{abstract}
Coal fly ashes and metallurgical slags are currently widely used as supplementary cementitious materials in production of Portland cement-based concretes. However, this application makes very poor use of the intrinsic reactivity of the glassy phases present in the waste materials, and can hardly therefore be considered 'valorisation' in the true sense of the word. Addition of these materials to Portland cements can also cause difficulties in early strength development, limiting their use to certain applications. Geopolymerisation, on the other hand, makes full use of the glassy ash and slag materials by using them as the key reactants in synthesis of aluminosilicate gel binders for waste-based concrete production. The activation of the glassy phases by alkaline solutions provides the opportunity to greatly reduce the Portland cement content of a concrete, but requires a sound understanding of the ash chemistry and its effects on workability, water demand and setting time if it is to be implemented successfully on a commercial scale. In this paper, various aspects of fly ash valorisation via geopolymerisation are discussed, including in particular the determination of ash reactivity by a recently-developed technique utilising dilatometric data. The correlations between ash reactivity as measured by dilatometry and geopolymer mechanical strength are discussed in detail, and comparisons with other measures of ash reactivity presented. Some commercial examples of geopolymer concrete in-place are also discussed to highlight these differences in real world usage.
\end{abstract}

KEYWORDS: Geopolymer, Fly ash, Valorisation, Concrete.

\section{INTRODUCTION}

Geopolymers are a class of aluminosilicate-based materials with the potential to replace Portland cement in a variety of applications, particularly where chemical or thermal resistance is required. Geopolymers for use in concrete production are generally synthesised by alkaline or alkali-silicate activation of coal fly ash and/or metallurgical slags (Duxson et al. 2007a), although the use of metakaolin (calcined kaolinite clay) or synthetic aluminosilicate precursors is of value in some applications and to provide a chemically simpler system for detailed scientific analysis (Duxson et al., 2005a; 2005b; Provis et al., 2005; van Deventer et al., 2007; Fernández-Jiménez et al., 2008).

The potential use of geopolymers to immobilise hazardous wastes is also of great interest as industries worldwide attempt both to remediate contaminated sites and to minimise the need for future remediation projects. It has long been proposed that geopolymers may be useful in immobilisation of hazardous waste streams (Davidovits and Comrie, 1988), but early work in this area was hindered somewhat by the relatively high porosity of metakaolin-based geopolymers (Khalil and Merz, 1994). However, the development of fly ash-based geopolymers over the past decade or more has provided significant advances in this area (van Jaarsveld et al., 1997; van Jaarsveld et al., 1999). Hazardous elements that have been successfully immobilised in geopolymers include As, B, Cd, Cr, Cs, Cu, Pb and $\mathrm{Sr}$ (Zosin et 
al., 1998; van Jaarsveld et al., 1999; Palomo and López de la Fuente, 2003; Palomo and Palacios, 2003; Fernández-Jiménez et al., 2005a; b; Perera et al., 2006; Blackford et al., 2007; Álvarez-Ayuso et al., 2008; Zhang et al., 2008a; 2008b). Some transition metals remain problematic (van Deventer et al. 2007), however the success of geopolymer technology in treating these species (including some which are very difficult to immobilise effectively in Portland cement matrices) shows that it is likely to be of significant value in treatment of wastes from industries such as minerals extraction and nuclear power generation. The ability to use a product derived from waste materials (fly ash and slag) in treatment of other industrial waste streams will be of highly significant value if the international chemical, power and minerals industries are to move closer to sustainable operation, as the use of 'virgin' resources in waste treatment must obviously be minimised as far as is possible.

Additionally, the concepts of geopolymer technology can be valuable in the valorisation of blast furnace and other slags by their use as a raw material in concrete production. While blast furnace slags have been relatively widely used as a supplementary cementitious material in alkali-activated and more standard Portland cement concretes for some time (Douglas et al., 1992; Wang and Scrivener, 1995), the use of various, often lower-calcium, non-blast furnace slags in alkali-activated systems is gaining increasing interest at present. These materials (including steel slags, phosphorus slags, ferronickel slags and others) are in general much less amenable to use in Portland cements, but which have been shown to be suitable for use in alkaline activation (Zosin et al., 1998; Shi et al., 2006; Komnitsas et al., 2007). Valorisation of these underutilised materials will therefore be of very significant benefit, if only as a means of preventing their heavy metal components from leaching into the environment from landfills.

Portland cement production is one of the largest commodity chemical processes worldwide, and is responsible for a very significant contribution to atmospheric pollution. The calcination of limestone and silica to form the highly reactive cement clinker requires an enormous amount of (usually fossil-fuel-derived) energy, and the inherent chemistry of the calcination reaction results in the emission of yet more $\mathrm{CO}_{2}$ (Humphreys and Mahasenan, 2002; Taylor et al., 2006). Alternative sources of energy are being actively sought by the cement industry in an attempt to reduce emissions (Damtoft et al., 2008), and various arguments with differing degrees of validity (such as the argument that burning carbon-containing wastes may be able to be counted as 'Greenhouse-positive' because the carbon is released as $\mathrm{CO}_{2}$ rather than forming $\mathrm{CH}_{4}$ in landfills) have been proposed to try to minimise the attribution of the $\mathrm{CO}_{2}$ emissions to different aspects of the cement production process.

In contrast, the solid raw materials used in geopolymer synthesis do not require calcination to render them chemically active. Coal-fired power stations and blast furnaces generate sufficiently high temperatures to produce fly ash or slag in a glassy state. This is not as reactive as the highly depolymerised calcium silicates which comprise the majority of a cement clinker, but is still able to react in an aqueous environment under the correct conditions. Chemical activation, by the use of alkaline hydroxide or silicate solutions, gives the necessary dissolution of glassy phases, with subsequent reprecipitation producing a strongly bonded covalent aluminosilicate framework. While there is some $\mathrm{CO}_{2}$ generated in the production of the alkaline activating solutions, detailed calculations (Duxson et al., 2007b) show that savings on the order of $80-90 \%$ are possible when comparing geopolymers to Portland-based cements. However, not all ashes and/or slags are 'created equal' (Duxson and Provis, 2008), and so further study is necessary to provide suggestions for researchers attempting to identify suitable raw materials for geopolymer synthesis.

\section{MATERIALS AND METHODS}

Geopolymer samples were prepared by mixing coal fly ashes (sourced from Australian power stations) with sodium or potassium silicate activating solutions of composition $\mathrm{M}_{2} \mathrm{O} . \mathrm{mSiO}_{2} \cdot 11 \mathrm{H}_{2} \mathrm{O}$, where $\mathrm{M}$ is $\mathrm{Na}$ or $\mathrm{K}$, and $m=0,0.5,1.0,1.5$ and 2.0. Binders tested to compare ash sources were formulated with approximately constant workability (empirically determined), while binders used to compare the effects of varying activator composition were formulated according to the specific desired liquid/solid mass ratios. Samples were cured at $40^{\circ} \mathrm{C}$ for 3 or 7 days as noted. Dilatometry was carried out using a Perkin-Elmer Diamond 
Thermomechanical Analyser, with $3 \mathrm{~mm}$ diameter $\times 5 \mathrm{~mm}$ length cylindrical paste samples and a heating rate of $10^{\circ} \mathrm{C} \mathrm{min}{ }^{-1}$. Mechanical strength testing utilised $50 \mathrm{~mm}$ mortar cubes, with sand/binder ratios of 2.1:1. The compositions of the ashes tested are listed in Table 1.

Table 1. Oxide compositions of ashes tested, from X-ray fluorescence

\begin{tabular}{ccccccccc}
\hline \multirow{2}{*}{ Source } & \multicolumn{7}{c}{ Oxide composition } \\
\cline { 2 - 9 } & $\mathrm{SiO}_{2}$ & $\mathrm{Al}_{2} \mathrm{O}_{3}$ & $\mathrm{CaO}$ & $\mathrm{MgO}$ & $\mathrm{Fe}_{2} \mathrm{O}_{3}$ & $\mathrm{Na}_{2} \mathrm{O}$ & $\mathrm{K}_{2} \mathrm{O}$ & Other \\
\hline Callide & 46.2 & 26.5 & 9.9 & 1.2 & 8.5 & 0.3 & 0.6 & 6.8 \\
Eraring & 67.8 & 21.6 & 1.7 & 0.4 & 3.0 & 0.1 & 1.2 & 4.2 \\
Bayswater & 62.9 & 24.9 & $<0.1$ & 1.0 & 5.2 & 0.2 & 1.3 & 4.5 \\
Vales Point & 65.0 & 20.3 & 5.6 & 0.9 & 4.5 & 0.5 & 1.7 & 1.5 \\
Mount Piper & 68.5 & 23.5 & 0.4 & 0.3 & 1.6 & $<0.1$ & 2.3 & 3.4 \\
Gladstone & 47.5 & 33.2 & 2.6 & 1.8 & 10.2 & $<0.1$ & 0.2 & 4.5 \\
\hline
\end{tabular}

\section{RESULTS AND DISCUSSION}

\subsection{Strength and dilatometry}

Figure 1 shows the variation in compressive strength for geopolymer mortars synthesised from fly ashes obtained from different Australian coal-fired power stations. Samples were all made with the same activator composition, with solid/liquid ratios selected to provide approximately equal workability in all cases. Figure 2 shows dilatometric data for geopolymer paste samples of the same compositions. There is a clear correspondence in these data between the samples that display good thermal stability and those which develop high strengths. The samples synthesised from ashes from Mt Piper and Vales Point develop effectively no strength during 1 week's curing at $40^{\circ} \mathrm{C}$, and show a severe expansion upon heating to relatively low temperature, consistent with the presence of a great deal of unreacted silicate activator and a corresponding low extent of reaction. Eraring and Bayswater ashes display moderate strength development and small thermal expansion following an initial period of shrinkage. Geopolymers synthesised from Gladstone and Callide ashes, which show the highest strength, do not show any expansion at this specific activator composition.

This then provides what appears to be a relatively sensitive measure of the extent of reactivity of a given ash in geopolymerisation. Ashes with poor reactivity show low strength and significant expansion upon heating of the geopolymer product, while ashes of higher reactivity show a dilatometric trace that is free of any expansion peaks. Dilatometry is a technique for which relatively small samples are able to be easily and reliably tested, reducing the volume of material that is required for preliminary characterisation of ash reactivity when compared to the preparation of multiple replicate samples for compressive strength testing.

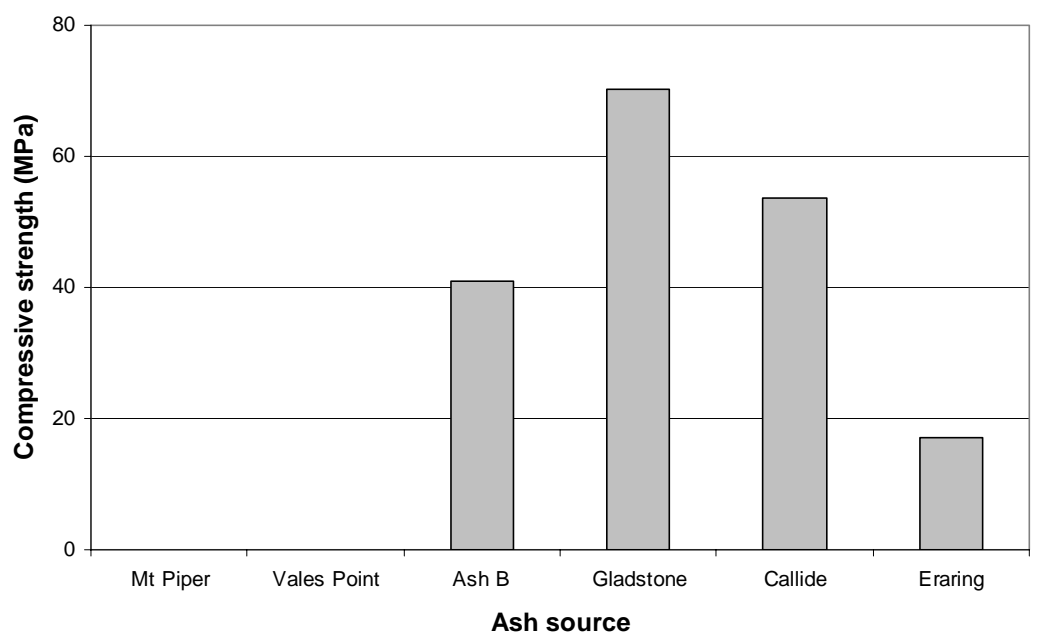

Figure 1. Compressive strengths (after 7 days' curing at $40^{\circ} \mathrm{C}$ ) of geopolymer mortars derived from ashes from different Australian coal-fired power stations, using the same activator composition $\left(\mathrm{SiO}_{2} / \mathrm{K}_{2} \mathrm{O}=1.0\right)$ and with equal workability. Samples plotted as zero strength had failed to harden in this curing regime 


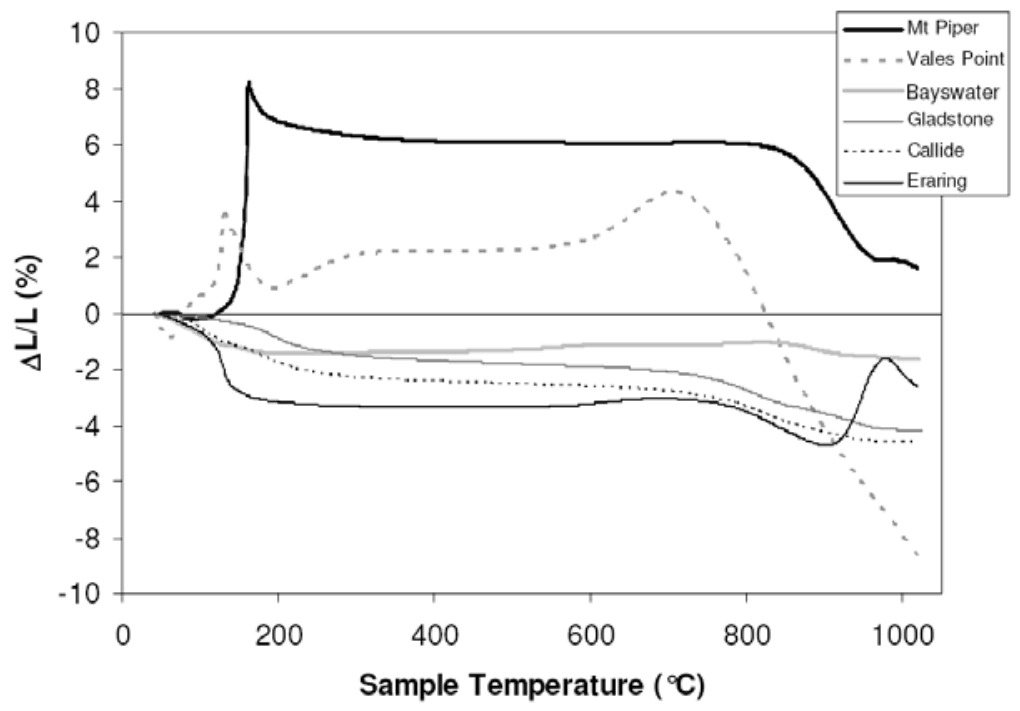

Figure 2. Dilatometric data for geopolymer pastes of the same compositions as in Figure 1

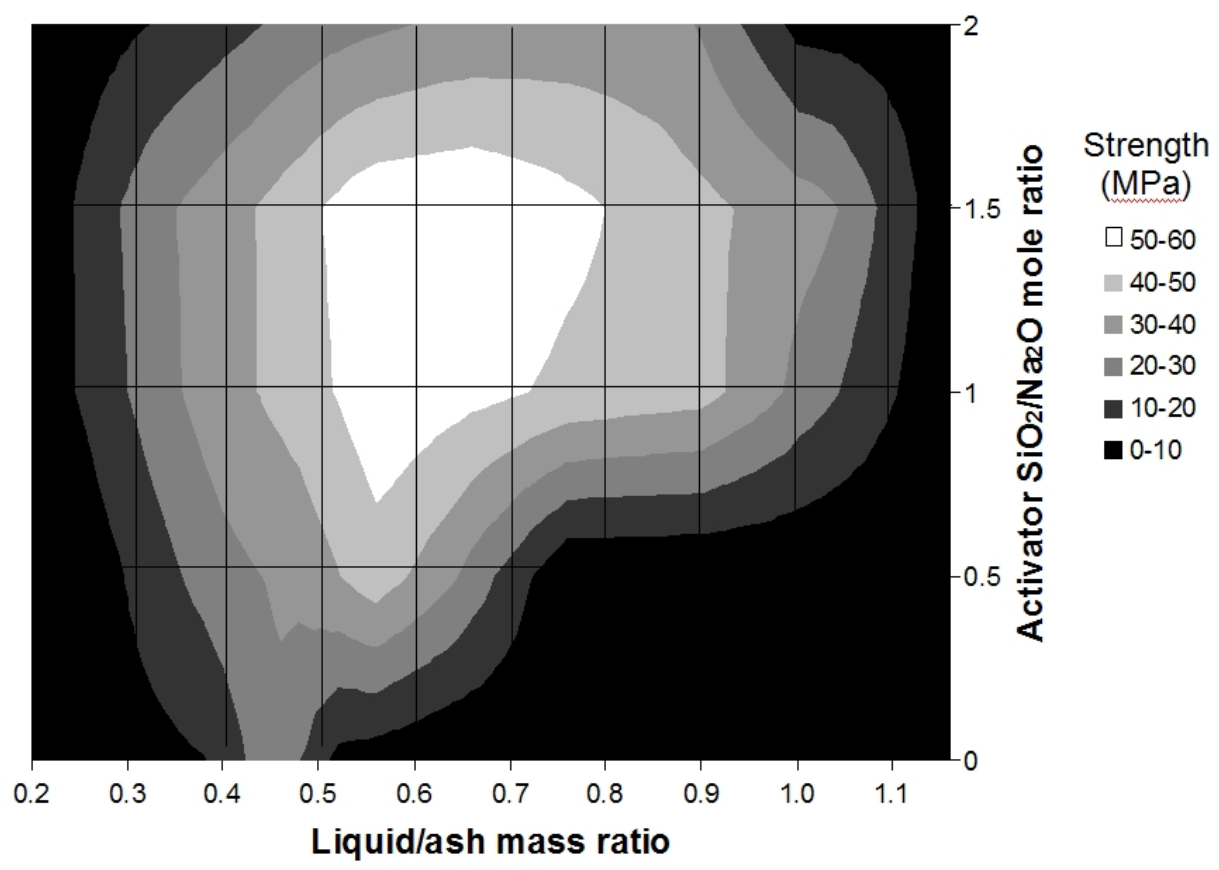

Figure 3. Variation of compressive strength with composition for mortars synthesized from Gladstone fly ash and sodium silicate activating solutions, cured at $40^{\circ} \mathrm{C}$ for 7 days. Adapted from Provis et al. (2009).

Figure 3 shows the effects of two other critical parameters on the mechanical strengths of fly ash-derived geopolymers: activator composition and activator/ash mass ratio. Data for a single ash source (Gladstone power station, Queensland, Australia) are presented here; a similar plot was presented by Rowles and O'Connor (2003) for metakaolin-derived geopolymers, but few other systematic and detailed analyses are available in the literature. It is obvious from this plot that there is a compositional 'sweet spot' for this specific ash, with an activator/ash mass ratio of around 0.6 and an activator composition of $\mathrm{Na}_{2} \mathrm{O}$ (1.01.5) $\mathrm{SiO}_{2} \cdot 11 \mathrm{H}_{2} \mathrm{O}$ providing optimal strength development during 7 days' curing at $40^{\circ} \mathrm{C}$. The location of this optimum will also depend to some extent on the water/alkali molar ratio of the activating solution (which was held fixed here), as well as the alkali metal used ( $\mathrm{Na}, \mathrm{K}$, or mixtures of Group 1 elements). However, closer investigation of Figure 3 indicates that, while the liquid/ash mass ratio is a useful engineering parameter to use in analysis of different mix designs, it is more likely that the molar ratio of alkali to solids is more significant in 
determining strength. This is because the optimal strengths for each activator composition fall on a diagonal 'ridge' on this plot, peaking at lower liquid/ash mass ratios for activating solutions containing less $\mathrm{SiO}_{2}$. This corresponds with a relationship between strength and molar alkali content, as a given mass of solution at higher $\mathrm{SiO}_{2} / \mathrm{Na}_{2} \mathrm{O}$ ratio will contain relatively less alkali than if less silica were present. Thus, regardless of the activator composition, the $\mathrm{Na}_{2} \mathrm{O} / \mathrm{ash}$ ratio predominantly controls the position of the maximum in strength; the $\mathrm{SiO}_{2} / \mathrm{Na}_{2} \mathrm{O}$ ratio then determines the maximum strength achievable, but not its position on the compositional diagram.

\subsection{Commercialisation of geopolymer technology}

The scientific literature as a whole demonstrates a relatively sophisticated level of understanding of the chemical and physical processes controlling the formation and structure of geopolymers. It is demonstrated in the literature that the properties of geopolymers can be engineered by tailoring binder chemistry, enabling the formulation of a diverse range of materials capable of performing in many applications in the construction and building products industry, but also in the inorganic glue, high-tech ceramic and refractory brick markets (Kriven et al., 2006; Duxson et al., 2007a; Davidovits, 2008; Pacheco-Torgal et al., 2008). What has not to date been demonstrated so publicly are commercially applied examples of geopolymer technology in use in the Western world. This appears to be for the most part an issue of business-related factors rather than those dealing with a technological hurdle, although it is clear that quality control and scale-up issues must be dealt with. Geopolymer-like products such as Pyrament ${ }^{\circledR}$ (Wheat, 1992) have seen brief commercial utilisation over the past 30 years, and alkali-slag cements have been very successfully used in the former Soviet Union (Krivenko, 1994; 2002), but large-scale commercial success has generally been elusive. However, the world's first commercial geopolymer concrete batching operation has opened in Melbourne, Australia during 2008, gaining significant media attention in the current environment where environmental gains are increasingly being viewed as important (Nowak, 2008).

It is also of interest to note that Malone et al. (1985), in a U.S. Army technical report, highlighted four aspects of alkali-activation technology that were at that time of particular relevance to the military establishment: assessment of the state of the art in alkali activation, development of heat-curing technology, additives to control setting and rheology, and guidelines for mix formulation (including aggregate mix design). Of these four issues, all are still of major importance in the commercialisation of geopolymers. Assessment of the state of the art in research is of obvious importance to a producer wishing to gain an advantage over competitors. Heat curing is not required for geopolymer concretes if the formulations are designed for ambient-temperature setting, but has been used in the production of larger structural members including geopolymer concrete columns (Sumajouw et al., 2007) and railway sleepers (Palomo et al., 2007). Developments in admixtures and additives for Portland cement are leading to much discussion regarding the transferability of these products to the geopolymer system, and the ability to design an optimal blend of aggregates is obviously essential in the success of any concrete, geopolymer or traditional.

The current challenge for geopolymer technology is therefore to become established as a recognised, viable, and proven technology that can be utilised in a range of applications. Most specifically, this involves having products available in the marketplace. Many published studies, as noted above, have independently verified the favourable material properties of geopolymers under various circumstances. However, without a product in the marketplace, the technology lacks 'real-world status', and risks being regarded as a laboratory solution that is of purely academic interest but impossible to implement in the practical context. Despite the commercial and technical drivers for the further development and commercialisation of geopolymer technology (Duxson et al., 2007b), there are a number of barriers that remain, in particular raw material access and market access.

Many lessons should be learnt from the success and track-record of the construction industry in the $20^{\text {th }}$ century to date, such as quality control, conservatism and long-term stability. However, it is also due to this conservatism and the reliance of the entire industry on what can basically be described as a single product line (Portland cement and its derivatives) that 
an environment exists which hinders innovation and the uptake of new, yet low-risk alternative technologies. Gartner (2004) and Phair (2006) have each provided a brief overview of some alternative binder technologies which may bring environmental benefits, but each stopped short of actually recommending any of the technologies discussed, for various reasons but predominantly due to the incomplete 'real-world' testing data available for most non-Portland cements. In order to develop a geopolymer industry, it is necessary to gain greater acceptance of the technology by potential manufacturers and end-users. This is a two-way process, where both technical and commercial virtues must be communicated to industry in a coherent and clear manner, while industry partners must embrace more extensive innovation and learn the benefits of multiple non-competitive product lines. This can be achieved through a more open dialogue approach between academia and industry, and also the wider dissemination of basic knowledge.

\section{CONCLUSIONS}

Geopolymer technology is clearly an area of importance as the world attempts to move towards a sustainable worldwide economy, because it provides the opportunity for both waste beneficiation/valorisation and immobilisation, while providing an alternative to a highly polluting existing technology. As such, research into the structure, kinetics, rheology and durability of geopolymers is expanding rapidly worldwide. Methods for characterising both geopolymers and raw material streams are increasingly providing the opportunity to screen suitable precursors rapidly and inexpensively, and the ever-developing understanding of both chemistry and engineering aspects of geopolymer synthesis is providing more accurate control over material properties.

Simultaneously, larger-scale commercialisation of geopolymer technology is beginning to show that aluminosilicate alternatives to Portland cement are in fact viable in precast and ready-mix concrete production. The further development of this class of materials requires a close synergy between research and commercialisation efforts. The 'green' edge of geopolymer technology is providing a major new driver in the adoption of the technology throughout the world.

\section{ACKNOWLEDGEMENTS}

This work was funded by financial support from the Australian Research Council (ARC), including some funding from the Particulate Fluids Processing Centre, a Special Research Centre of the ARC.

\section{REFERENCES}

Álvarez-Ayuso, E., Querol, X., Plana, F., Alastuey, A., Moreno, N., Izquierdo, M., Font, O., Moreno, T., Diez, S., Vázquez, E. and Barra, M., (2008), Environmental, physical and structural characterisation of geopolymer matrixes synthesised from coal (co-)combustion fly ashes, Journal of Hazardous Materials, 154, 175-183.

Blackford, M.G., Hanna, J.V., Pike, K.J., Vance, E.R. and Perera, D.S., (2007), Transmission electron microscopy and nuclear magnetic resonance studies of geopolymers for radioactive waste immobilization, Journal of the American Ceramic Society, 90, 1193-1199.

Damtoft, J.S., Lukasik, J., Herfort, D., Sorrentino, D. and Gartner, E., (2008), Sustainable development and climate change initiatives, Cement and Concrete Research, 38, 115-127.

Davidovits, J., (2008), Geopolymer Chemistry and Applications, Institut Géopolymère, SaintQuentin, France.

Davidovits, J. and Comrie, D.C., (1988), Long term durability of hazardous toxic and nuclear waste disposals. In: Proceedings of Geopolymer '88 - First European Conference on Soft Mineralurgy, Davidovits J. and Orlinski J. (eds.), Universite de Technologie de Compeigne: Compeigne, France.

Douglas, E., Bilodeau, A. and Malhotra, V.M., (1992), Properties and durability of alkali-activated slag concrete, ACl Materials Journal, 89, 509-516.

Duxson, P., Fernández-Jiménez, A., Provis, J.L., Lukey, G.C., Palomo, A. and van Deventer, J.S.J., (2007a), Geopolymer technology: The current state of the art, Journal of Materials Science, 42, 2917-2933. 
Duxson, P. and Provis, J.L. (2008), Designing precursors for geopolymer cements, Journal of the American Ceramic Society, 91, 3864-3869.

Duxson, P., Provis, J.L., Lukey, G.C., Mallicoat, S.W., Kriven, W.M. and van Deventer, J.S.J., (2005a), Understanding the relationship between geopolymer composition, microstructure and mechanical properties, Colloids and Surfaces A - Physicochemical and Engineering Aspects, 269, 47-58.

Duxson, P., Provis, J.L., Lukey, G.C., Separovic, F. and van Deventer, J.S.J., (2005b), ${ }^{29}$ Si NMR study of structural ordering in aluminosilicate geopolymer gels, Langmuir, 21, 3028-3036.

Duxson, P., Provis, J.L., Lukey, G.C. and van Deventer, J.S.J., (2007b), The role of inorganic polymer technology in the development of 'Green concrete', Cement and Concrete Research, 37, 1590-1597.

Fernández-Jiménez, A., Macphee, D.E., Lachowski, E.E. and Palomo, A., (2005a), Immobilization of cesium in alkaline activated fly ash matrix, Journal of Nuclear Materials, 346, 185-193.

Fernández-Jiménez, A., Monzó, M., Vicent, M., Barba, A. and Palomo, A., (2008), Alkaline activation of metakaolin-fly ash mixtures: Obtain of Zeoceramics and Zeocements, Microporous and Mesoporous Materials, 108, 41-49.

Fernández-Jiménez, A., Palomo, A., Macphee, D.E. and Lachowski, E.E., (2005b), Fixing arsenic in alkali-activated cementitious matrices, Journal of the American Ceramic Society, 88, 11221126.

Gartner, E., (2004), Industrially interesting approaches to "low- $\mathrm{CO}_{2}$ " cements, Cement and Concrete Research, 34, 1489-1498.

Humphreys, K. and Mahasenan, M., (2002), Toward a sustainable cement industry, Substudy 8: Climate change, Batelle and World Business Council for Sustainable Development, 92pp.

Khalil, M.Y. and Merz, E., (1994), Immobilization of intermediate-level wastes in geopolymers, Journal of Nuclear Materials, 211, 141-148.

Komnitsas, K., Zaharaki, D. and Perdikatsis, V., (2007), Geopolymerisation of low calcium ferronickel slags, Journal of Materials Science, 42, 3073-3082.

Kriven, W.M., Kelly, C.A. and Comrie, D.C., (2006), Geopolymers for structural ceramic applications, Report FA9550-04-C-0063, Air Force Office of Scientific Research, 144pp.

Krivenko, P.V., (1994), Alkaline cements. In: Proceedings of the First International Conference on Alkaline Cements and Concretes, Kiev, Ukraine, Krivenko P.V. (ed.), VIPOL Stock Company: 11-129.

Krivenko, P.V., (2002), Alkaline cements: From research to application. In: Geopolymers 2002. Turn Potential into Profit, Melbourne, Australia, Lukey G.C. (ed.), Siloxo Pty. Ltd., CD-ROM Proceedings.

Malone, P.G., Randall, C.J. and Kirkpatrick, T., (1985), Potential applications of alkali-activated aluminosilicate binders in military operations. Geotechnical Laboratory, Department of the Army, Washington DC, USA.

Nowak, R., (2008), Geopolymer concrete opens to reduce $\mathrm{CO}_{2}$ emissions, New Scientist, 197, 2829.

Pacheco-Torgal, F., Castro-Gomes, J. and Jalali, S., (2008), Adhesion characterization of tungsten mine waste geopolymeric binder. Influence of OPC concrete substrate surface treatment, Construction and Building Materials, 22, 154-161.

Palomo, A., Fernández-Jiménez, A., López-Hombrados, C. and Lleyda, J.L., (2007), Railway sleepers made of alkali activated fly ash concrete, Revista Ingeniería de Construcción, 22, 75-80.

Palomo, A. and López de la Fuente, J.I., (2003), Alkali-activated cementitious materials: Alternative matrices for the immobilisation of hazardous wastes - Part I. Stabilisation of boron, Cement and Concrete Research, 33, 281-288.

Palomo, A. and Palacios, M., (2003), Alkali-activated cementitious materials: Alternative matrices for the immobilisation of hazardous wastes - Part II. Stabilisation of chromium and lead, Cement and Concrete Research, 33, 289-295.

Perera, D.S., Vance, E.R., Aly, Z., Davis, J. and Nicholson, C.L., (2006), Immobilization of Cs and $\mathrm{Sr}$ in geopolymers with Si/Al $\sim 2$, Ceramic Transactions, 176, 91-96.

Phair, J.W., (2006), Green chemistry for sustainable cement production and use, Green Chemistry, 8, 763-780. 
Provis, J.L., Lukey, G.C. and van Deventer, J.S.J. (2005), Do geopolymers actually contain nanocrystalline zeolites? - A reexamination of existing results, Chemistry of Materials, 17, 3075-3085.

Provis, J.L., Yong, C.Z., Duxson, P. and van Deventer, J.S.J. (2009), Correlating mechanical and thermal properties of sodium silicate-fly ash geopolymers, Colloids and Surfaces A Physicochemical and Engineering Aspects, 336, 57-63

Rowles, M. and O'Connor, B. (2003), Chemical optimisation of the compressive strength of aluminosilicate geopolymers synthesised by sodium silicate activation of metakaolinite, Journal of Materials Chemistry, 13, 1161-1165.

Shi, C., Krivenko, P.V. and Roy, D.M., (2006), Alkali-Activated Cements and Concretes, Taylor \& Francis, Abingdon, UK.

Sumajouw, D.M.J., Hardjito, D., Wallah, S.E. and Rangan, B.V., (2007), Fly ash-based geopolymer concrete: Study of slender reinforced columns, Journal of Materials Science, $\mathbf{4 2}$, 3124-3130.

Taylor, M., Tam, C. and Gielen, D. (2006), Energy efficiency and $\mathrm{CO}_{2}$ emissions from the global cement industry, International Energy Agency.

van Deventer, J.S.J., Provis, J.L., Duxson, P. and Lukey, G.C., (2007), Reaction mechanisms in the geopolymeric conversion of inorganic waste to useful products, Journal of Hazardous Materials, A139, 506-513.

van Jaarsveld, J.G.S., van Deventer, J.S.J. and Lorenzen, L. (1997), The potential use of geopolymeric materials to immobilise toxic metals. 1. Theory and applications, Minerals Engineering, 10, 659-669.

van Jaarsveld, J.G.S., van Deventer, J.S.J. and Schwartzman, A. (1999), The potential use of geopolymeric materials to immobilise toxic metals: Part II. Material and leaching characteristics, Minerals Engineering, 12, 75-91.

Wang, S.D. and Scrivener, K.L., (1995), Hydration products of alkali-activated slag cement, Cement and Concrete Research, 25, 561-571.

Wheat, H.G. (1992), Corrosion behavior of steel in concrete made with Pyrament $\circledast$ blended cement, Cement and Concrete Research, 22, 103-111.

Zhang, J., Provis, J.L., Feng, D. and van Deventer, J.S.J., (2008a), Geopolymers for immobilization of $\mathrm{Cr}^{6+}, \mathrm{Cd}^{2+}$, and $\mathrm{Pb}^{2+}$, Journal of Hazardous Materials, 157, 587-598.

Zhang, J., Provis, J.L., Feng, D. and van Deventer, J.S.J., (2008b), The role of sulfide in the immobilization of $\mathrm{Cr}(\mathrm{VI})$ in fly ash geopolymers, Cement and Concrete Research, 38, 681688.

Zosin, A.P., Priimak, T.I. and Avsaragov, K.B., (1998), Geopolymer materials based on magnesiairon slags for normalization and storage of radioactive wastes, Atomic Energy, 85, 510-514. 